\title{
AN INVESTIGATION INTO THE PURPOSES, ACCURACY, AND EFFECTIVE USES OF THE BLIND REGISTER IN ENGLAND
}

\author{
MARY E. BRENNAN AND E. G. KNOX \\ Department of Social Medicine, University of Birmingham Medical School
}

A register is a list of the names of persons with a particular attribute. In a research setting the names may be used to avoid erroneous double entry, or to link sequential entries, or to link one register with another; but in a service setting, the chief purpose of identifying individuals is to deliver some service to them. This is at least implicit and it is doubtful whether we should characterize as a service-register any listing process which omits the efferent step. The problems of running medical registers for cancer patients (British Medical Journal, 1963; Acheson, 1968), tuberculous patients (Tubercle, 1964), and patients with mental illness (British Medical Journal, 1968) have been well described; likewise the hazards of running an 'at risk' register (Thomas, 1968) and a kidney transplant register (Hopewell, 1966). These studies demonstrate comprehensively the technical difficulties of $(a)$ establishing appropriate criteria for admission, (b) ensuring that all appropriate staff are aware of the criteria, (c) providing multiple access to the register through different agencies, and $(d)$ ensuring confidentiality. Continued systematic investigation of this kind of register therefore seems useful, especially in the context of the changing health service administrative system. The Blind Register has been chosen as the particular object of the present study. The Blind Register has all the problems of the medical registers described above and, in addition, although it is used for medical research and medical administration, its primary purposes are not medical. Registers with multiple uses deserve special attention at the present time when new arrangements are separating responsibilities previously linked within a single administrative system.

\section{PURPoses}

The Blind Register accepts patients defined under the National Assistance Act 1948 as 'so blind as to be unable to perform any work for which eye-sight is essential'. This Act complements the previous legislation of the Blind Persons Act 1938 and the Local Government Act 1929. The BD8 Form used for registration states that 'the test is not whether the person is unable to pursue his ordinary occupation or any particular occupation, but whether he is too blind to perform any work for which eyesight is essential', and that 'only visual conditions are taken into account'. Other bodily or mental infirmities are disregarded. Usually a person with a visual acuity below $3 / 60$ Snellen in both eyes may be regarded as blind and a person with visual acuity of $3 / 60$ but less than $6 / 60$ is regarded as blind if the field of vision is considerably contracted.

The statutory benefits available for the registered blind are:

1. An additional $£ 100$ may be earned before taxation becomes effective; from 6 April 1973 this is increased to $£ 130$.

2. A higher rate of supplementary benefit is available to those who are eligible.

3. Supplementary benefits are available to dependants of those blind people who are unemployed or unemployable.

4. No payment is required for a sighted guide who travels with the blind person on business on British Rail.

There are additional benefits for particular groups. The Blind Children's Education Act 1893 is still effective and it provides appropriate educational facilities for blind and partially sighted children. Local Authorities must supply instruction in handicrafts and sewing, and training in appropriate forms of employment, as well as radios and braille typing machines. Some Local Authorities provide free bus passes and special allowances and subsidies for household adaptations. Most of these additional benefits do not accrue to patients who are not registered and this is particularly true of financial benefits. Because the blind are disabled, the Local Authority has an additional statutory duty under the Chronically Sick and Disabled Persons Act 1970 to ensure that they are made aware of any services in 
their area which provide for their needs. The Disabled Persons Employment Acts 1944/1958 require the Minister responsible for employment to establish District Advisory Committees and assessment panels which recommend the entry of names to a register giving access to designated employment. Blind patients may also be registered in this way, although there are no formal administrative arrangements for automatic transfer from one register to the other. A register of the partially sighted is also maintained by each authority, in this case under the direction of the Ministry of Health circular $15 / 48$. A later circular $4 / 63$ advised that the partially sighted should also have access to the welfare services.

The primary objective of the Blind Register appears to be the identification of individuals for whom welfare measures may be undertaken, including the provision of appropriate education and care, financial assistance, work placement, and sheltered employment where necessary. An additional objective of planning local and national services is implied from the amalgamation of Local Authority registers into a National Register. This is compiled by the Department of Health and Social Security

\section{TABLE I}

INFORMATION AVAILABLE BY STANDARD REGION AND LOCAL AUTHORITY (from analysis of Forms SBL 657-660 DHSS 1971)

$\begin{array}{ll}\begin{array}{l}\text { Blind } \\ \text { (1) Numbers registered }\end{array} & \begin{array}{l}\text { (a) Total number } \\ \text { (b) Rate per } 105\end{array} \\ & \text { (c) Number aged } 65 \text { years and } \\ \text { over }\end{array}$

which suggests that medical planning as well as social service planning is an intended function. The National Register has also been used in both population-genetic and sociological studies (Sorsby, 1966; Gray and Todd, 1967).

\section{CONTENT}

Data derived from the BD8 registration forms are collated by each Local Authority according to the specification of forms SPL 657-660 and sent to the Department of Health and Social Security. Details of the partially sighted register are also submitted on this form (Table I). The numbers in the various categories at different ages for the whole of England and Wales are given in Table IIa.

An analysis conducted in England only (Report of the Department of Health and Social Security, 1971) gave numbers in each authority and all ages, and in the age groups 5-15 years, 16-64 years, and over 65 years, but the number aged $0-4$ years was not given and can be inferred only indirectly by subtracting the later age groups from the total. Total prevalence and annual incidence rates at all ages and for those over 65 years were also given but the rates for the

TABLE IIA

AGE DISTRIBUTION OF REGISTERED BLIND AT DECEMBER 1967 IN ENGLAND AND WALES

\begin{tabular}{|c|c|c|c|c|c|}
\hline Age & & Males & Females & Total & Percentage \\
\hline $\begin{array}{l}\text { Under } 1 \\
1-4 \quad \ldots \\
5-15 \quad \cdots \\
16-20 \quad \ldots \\
21-49 \quad \ldots \\
50-64 \quad \ldots \\
65 \text { and over } \\
\text { Not known }\end{array}$ & $\begin{array}{l}\ldots \\
\ldots \\
\ldots \\
\cdots \\
\ldots \\
\ldots\end{array}$ & $\begin{array}{r}5 \\
214 \\
987 \\
687 \\
6,260 \\
8,357 \\
23,466 \\
6\end{array}$ & $\begin{array}{r}7 \\
167 \\
791 \\
518 \\
4,468 \\
8,310 \\
48,341 \\
13\end{array}$ & $\begin{array}{r}12 \\
381 \\
1,778 \\
1,205 \\
10,728 \\
16,667 \\
71,807 \\
19\end{array}$ & $\begin{array}{r}0.0 \\
0.4 \\
1.7 \\
1.2 \\
10.5 \\
16 \cdot 2 \\
70.0 \\
0.0\end{array}$ \\
\hline$\overline{\text { Total .. }}$ & $\ldots$ & 39,982 & 62,615 & 102,597 & $100 \cdot 0$ \\
\hline
\end{tabular}

From: On the State of the Public Health, 1968 (1969). Department of Health and Social Security. H.M.S.O., London.

TABLe IIB

RATES OF REGISTERED BLINDNESS FOR ENGLAND IN 1970

(per $10^{5}$ in each age group)

\begin{tabular}{|c|c|c|c|}
\hline & Age Group & Prevalence Rate & Incidence Rate \\
\hline $\begin{array}{l}\text { Unweighted } \\
\text { mean of L.A. } \\
\text { areas }\end{array}$ & $\begin{array}{c}5-15 \\
16-64 \\
65+ \\
\text { Total }\end{array}$ & $\begin{array}{r}25 \cdot 0 \\
68 \cdot 5 \\
1,139 \cdot 2 \\
219 \cdot 9\end{array}$ & $\begin{array}{c}\text { Not available } \\
\text { Not available } \\
153.9 \\
25.5\end{array}$ \\
\hline Whole country & All ages & $207 \cdot 0$ & $24 \cdot 2$ \\
\hline
\end{tabular}


other age groups were not provided. The national figures were broken down fully into age sex categories but there was no equivalent breakdown by individual Local Authorities (Table IIb). In the age group 16-64 years, the mean national percentage employed was 31.8 and the rate of workshop provision was $3 \cdot 8 / 105$. The original registration form BD8 shows marital status and present and previous occupations. However, no analyses were given in terms of these factors. Form BD8 also shows the source of referral, details of other diseases present, prognosis, family history, and the recommendations of the registering doctor. However, these items are not always completed and the main loss of information may be at registration rather than at analysis.

\section{ACCURACY}

\section{EFFECTIVENESS}

No routine attempts to control the accuracy of individual registers are reported and no operational standards to this purpose are laid down. In addition, the mechanism of entry to the register is known not to be uniform. Entry is always through the certificate of a qualified ophthalmic specialist acting on behalf of the Local Authority but there is no regular cross checking of standards between different specialists and Local Authorities, and the pathway to the specialist itself varies. In some areas referrals are normally channelled through the Social Service Department while in others arrangements exist for consultants to certify patients before a formal application from the Social Service Department is received.

The rates of registered blindness in different English Local Authorities in 1970 (excluding the City of London) were examined to see if there were large discrepancies. A selection of prevalence and incidence rates by age group is given in Table III. It
TABLE III

COMPARISON OF AREAS WITH HIGH AND LOW RATES OF REGISTERED BLINDNESS

(per $10^{5}$ in each age group)

\begin{tabular}{|c|c|c|c|c|c|}
\hline \multirow{2}{*}{$\underset{\text { Area }}{\text { Administrative }}$} & \multicolumn{4}{|c|}{ Age (yr) } & \multirow[b]{2}{*}{ Total } \\
\hline & $0-4$ & $5-15$ & $16-64$ & $65+$ & \\
\hline $\begin{array}{ll}\text { Solihull } & . \\
\text { Oxfordshire } & \ldots \\
\text { Birmingham } & . \\
\text { Bromley } & \ldots \\
\text { Cumberland } & . \\
\text { South Shields } & . \\
\text { Oldham } & . \\
\text { Bournemouth } & . .\end{array}$ & $\begin{array}{r}12 \\
34 \\
242 \\
4 \\
234 \\
270 \\
87 \\
265\end{array}$ & $\begin{array}{l}49 \\
26 \\
16 \\
18 \\
55 \\
18 \\
12 \\
24\end{array}$ & $\begin{array}{r}28 \\
43 \\
59 \\
64 \\
57 \\
115 \\
143 \\
37\end{array}$ & $\begin{array}{r}516 \\
1,043 \\
785 \\
1,008 \\
1,149 \\
1,740 \\
1,784 \\
1,720\end{array}$ & $\begin{array}{r}78 \\
143 \\
154 \\
166 \\
210 \\
325 \\
342 \\
506\end{array}$ \\
\hline
\end{tabular}

shows pronounced variations at all ages, particularly in the younger groups. Variations were extreme in the 0-4 age group but the values in this age group were computed by difference and would therefore include all those of unstated age.

The tabulations contain many interesting contrasts. Bournemouth had a total prevalence of $506 / 105$, Solihull only $78 / 105$. Even within a single region (North West) Burnley had a prevalence of $312 / 10^{5}$ and Rochdale only $169 / 105$. Some of the inter-authority variation was related to differing population sizes, and the variations were morg pronounced in the smaller boroughs. Authorities with populations in excess of $0.5 \times 10^{6}$ displayed fof narrower range extending from Berkshire with prevalence of $133 / 105$ to Kent with $212 / 10^{5}$. The highest regional prevalence rate was $246 / 10^{5}$ in the South West and the lowest was $170 / 10^{5}$ in the West Midlands. Regional incidence rates for new cases in 1970 ranged from $19 \cdot 5 / 105 /$ year in the Northern Region to $29 \cdot 6 / 105 /$ year in the South West (Table IV).

Numbers were usually too small to permit comment upon the varying patterns for provision of education or sheltered employment in different Local Authority areas, but there were pronounced

TABLE IV

REGIONAL VARIATIONS IN RATES OF REGISTERED BLINDNESS (per $10^{5}$ population)

\begin{tabular}{|c|c|c|c|c|c|c|c|c|c|c|}
\hline \multirow{2}{*}{\multicolumn{3}{|c|}{ Region }} & \multicolumn{2}{|c|}{ Incidence Rates } & \multicolumn{4}{|c|}{ Prevalence Rates } & \multicolumn{2}{|c|}{ Per cent not suitable for } \\
\hline & & & Total & $\begin{array}{c}\text { Per cent } \\
65+\end{array}$ & Total & $5-15$ & $\begin{array}{c}\text { Age } \\
16-64\end{array}$ & $65+$ & $\begin{array}{l}\text { Any Form of } \\
\text { Education } \\
(5-15)\end{array}$ & $\begin{array}{l}\text { Any Form of } \\
\text { Employment } \\
\text { (16-64) }\end{array}$ \\
\hline $\begin{array}{l}\text { North } \\
\text { Yorkshire and } \\
\text { North West } \\
\text { East Midlands } \\
\text { West Midlands } \\
\text { East Anglia } \\
\text { South East } \\
\text { South West }\end{array}$ & $\begin{array}{c}\text { Humberside } \\
\ldots \\
\ldots \\
. \\
\ldots \\
\ldots \\
\ldots\end{array}$ & \begin{tabular}{l|}
$\cdots$ \\
$\cdots$ \\
$\cdots$ \\
$\cdots$ \\
$\cdots$ \\
$\cdots$
\end{tabular} & $\begin{array}{l}19 \cdot 5 \\
23 \cdot 1 \\
24 \cdot 1 \\
27 \cdot 4 \\
21 \cdot 5 \\
22 \cdot 1 \\
24 \cdot 6 \\
29 \cdot 6\end{array}$ & $\begin{array}{l}77 \\
80 \\
80 \\
81 \\
80 \\
82 \\
82 \\
83\end{array}$ & $\begin{array}{l}187 \cdot 7 \\
215 \cdot 2 \\
205 \cdot 9 \\
213 \cdot 6 \\
170 \cdot 0 \\
199 \cdot 5 \\
210 \cdot 6 \\
245 \cdot 9\end{array}$ & $\begin{array}{l}20 \cdot 3 \\
26 \cdot 1 \\
22 \cdot 5 \\
27 \cdot 9 \\
24 \cdot 3 \\
16 \cdot 0 \\
22 \cdot 4 \\
24 \cdot 3\end{array}$ & $\begin{array}{l}58 \cdot 7 \\
61 \cdot 4 \\
73 \cdot 4 \\
60 \cdot 6 \\
57 \cdot 0 \\
57 \cdot 6 \\
61 \cdot 5 \\
65 \cdot 7\end{array}$ & $\begin{array}{l}1,000 \cdot 0 \\
1,082 \cdot 8 \\
1,066 \cdot 0 \\
1,401 \cdot 9 \\
1,037 \cdot 0 \\
1,028 \cdot 0 \\
1,152 \cdot 0 \\
1,333 \cdot 3\end{array}$ & $\begin{array}{l}36 \cdot 0 \\
40 \cdot 7 \\
26 \cdot 7 \\
29 \cdot 5 \\
31 \cdot 3 \\
47 \cdot 5 \\
37 \cdot 8 \\
38 \cdot 5\end{array}$ & $\begin{array}{l}28 \cdot 4 \\
35 \cdot 6 \\
37 \cdot 9 \\
24 \cdot 5 \\
24 \cdot 2 \\
31 \cdot 2 \\
27 \cdot 6 \\
32 \cdot 1\end{array}$ \\
\hline
\end{tabular}


differences between regions although they are substantially larger than local administrative areas.

There was evidence of a positive association between the prevalence and incidence rates in different Local Authorities $(r=0.67, P<0.001)$ suggesting that whatever factors were responsible for the overall variation, they remained consistent over a period of time. Incidence rates of new cases on the Blind and Partially Sighted Registers were also positively associated $(\mathrm{r}=0.20,0.01<\mathrm{P}<$ 0.05 ). Variation in incidence and prevalence estimates for the registered blind was not therefore attributable to differential allocation to the Blind and Partially Sighted Registers.

In summary, there were substantial indications that the wide variations in incidence and prevalence were systematic. However, except in the case of the age group 0-4 years, where there was evidence that the variations were artefactual, there was little to show whether the variations reflected differing registration procedures or whether they reflected true inter-regional variations in the incidence and prevalence of blindness. Because of this it became necessary to relate the differing incidence and prevalence rates to the other known differences between regions and individual authorities.

\section{SOURCES OF VARIABILITY}

Different age structures in different populations clearly accounted for some of the variations. For example, much of the difference between Solihull's $78 / 10^{5}$ and Bournemouth's 506/105 arose from this cause and the difference, although still present, was much less within individual age groups. In the age group 16-64 years, Solihull's rate was 28/105 and Bournemouth's $37 / 105$, and in the age group 65 years and over the rate for Solihull was 1010/105 and for Bournemouth 1720/105. Part of the residual differences, here and in other comparisons, may have been due to differing distributions within these coarse groupings, especially in the oldest group, but the data supplied did not permit further analysis. General confirmation of the relationship between age distribution and registration was obtained through a positive association $(\mathrm{r}=+0.53$, $P<0.01)$ between the incidence rate and the proportion of elderly (65 years and over) in each administrative area. Nevertheless, the general picture contained interesting contrasts. For example, Bournemouth had a total prevalence of 506/105 and Brighton only $322 / 105$; the proportions of elderly persons did not differ greatly, $24.9 \%$ in Bournemouth compared with $20.2 \%$ in Brighton, but the prevalence estimates for persons over 65 years were $1720 / 10^{5}$ in Bournemouth and only $1200 / 10^{5}$ in
Brighton. Despite the impossibility of conducting full age standardizations, examples such as this suggest that overall variations in registration rates cannot be explained by demographic factors alone.

Several simple indices of socio-economic deprivation are available for the above boroughs, some of them reasonably direct and others less so. They include the infant mortality rate, the standardized mortality ratio for deaths from all causes, the rate of immigration from Commonwealth countries, and sulphur dioxide pollution levels. They were examined systematically in relation to the prevalence of blindness at all ages, and in each age group. There were no significant correlations for the infant mortality or immigration rates or for the concentration of sulphur dioxide in the atmosphere (data from the Warren Spring Laboratory, 1971) and the SMR was related to prevalence only in the age group 16-64 years $(\mathrm{r}=+0.37, \mathrm{P}<0.01)$.

The only other suggestion of a socio-economic effect was obtained by comparing the Administrative Counties and the County Boroughs with respect to the age group 16-64 years. The mean of the prevalences given for the Counties was $56 \cdot 2$ and that for the County Boroughs was $76 \cdot 8$. The Administrative Counties are mainly rural and the County Boroughs are urban and the population size of the Counties is, on the whole, greater than that of the County Boroughs.

Local Authority expenditures on blind persons were examined in relation to the prevalence of registered blindness. The overall expenditure was $£ 42.40$ per annum per blind person (the Institute of Municipal Treasurers and Accountants and the Society of County Treasurers, 1972). There was no correlation between expenditure per person and prevalence of registered blindness in any age group. No associations were detected with figures for expenditure per person on all welfare services, including blindness, or expenditure on welfare services for the handicapped. There was no correlation (age group 16-64 years only) between prevalence and either the proportion in sheltered employment or the proportion in training or seeking work. However, there was a small positive correlation between total prevalence and the proportion of the working age group classified as unfit for employment $(\mathrm{r}=+0.14 ; \mathrm{P}<0.1)$. If high registration rates had reflected more complete ascertainment of the 'marginally' blind, we would have expected high apparent prevalence to be associated with low proportions unfit for employment. A positive association runs counter to this expectation and suggests that lack of opportunity for suitable employment, and the need for supple- 
mentary benefits, may encourage registration. However, separate rates for males and females are not available for individual regions and it is not possible to be definitive here.

The rates of registered blindness in different age groups did not correlate significantly with each other, suggesting perhaps that the medical and social factors affecting the decision to register are quite different in the different age groups.

\section{Discussion}

The substantial variation in the registration rates might be attributed to any of several causes; $(a)$ irregularities arising from the small size of some populations or from inadequate registration arrangements; (b) differing age structures; (c) differences in the true incidence and prevalence of blindness, possibly reflected in the variations of socio-economic conditions; (d) different referral policies in different localities on the part of general practitioners, social workers, and consultants; and (e) unwillingness of certain social groups to identify themselves as blind because of cultural differences in the perceptions of blindness, disability, and dependency.

The effects of the first three factors are each clearly demonstrable but they do not explain the whole of the variation. Indeed, apart from the differences related to demographic structure the effect is probably not large, and the main causes of variation must probably be sought in the variations of behaviour found in patients, doctors, and social workers.

Zborowski (1960), Mechanic (1969), and other writers of the Interactionist School of Sociology have demonstrated the importance of varying definitions in the presentation of many illnesses and disabilities. The patient is willing to define himself as ill or disabled only when the psychological as well as the social benefits of such a definition exceed the psychological and social disadvantages. Many patients may be unwilling to be registered as blind for reasons of this kind, and may be supported or sanctioned in their views by their families, their general practitioners or specialists. A recent study in Glamorgan (Graham, Wallace, Welsby, and Grace, 1968) found that nine patients were not registered out of a total of 31 blind persons and a total population of about 1,600. This study was based on a small and possibly atypical population but indicated that registration was often not accepted because it was regarded as degrading and based on concepts of poor law 'charity'. Harris, Cox, and Smith (1971) showed that only $10 \%$ of the physically disabled were registered by Local
Authority Social Service Departments, although the percentage of registration in blind persons is probably much higher than this because of the special financial and other benefits which accrue. Nevertheless, a substantial degree of under reporting must occur for such reasons.

However, the very wide variations between similar authorities, sometimes in limited geographical areas, are unlikely to arise entirely from this cause because extreme variations in culture between adjoining local administrative areas would be necessary to explain the findings. The main source of the variability between authorities is likely to reside in different referral and registration patterns. The decision to refer a patient for registration may be taken by many agencies, for example general practitioners, consultants, relatives, and supplementary benefit officers. The route of referral may also vary from one authority to another, and some consultants may be unwilling to register as blind those patients seen initially in the outpatient setting and not referred through the Social Service Department. Consultants and social workers differ in their attitudes towards registration and some are probably unaware of the benefits and may fail to communicate the advantages of registration to the blind person. Elderly persons with slowly deteriorating vision may attend outpatient departments for many yearso supervised by doctors in the non-specialist grades? working in ophthalmic or other departments who may be unaware of the possibilities or the advantages of registration and therefore do not refer suitable patients.

The large variations in prevalence and incidence rates and the demonstrable importance of variations in the registration procedures indicate that many cases are not being identified. The higher figures found in some of the larger authorities are probably more accurate guides to national levels than are the means for all authorities. Evidence on this point is available from another source. Amelia Harris stated that about $7 \%$ of physical handicap over the age of 65 is caused by blindness or related eye disorders and considered that in the total population there were 143,000 persons handicapped because of blindness or partial sight (Harris et al., 1971). However, this was not a complete estimate because only the patient whose 'impairment limits in some way his getting about, working, or taking care of himself, or who has some physical impairment' was included. A proportion of the younger blind are not handicapped in this way and would have been excluded. The total number of patients registered in 1970 was 129,897 (95,724 blind; 34,173 partially sighted), which indicates that a substantial number 
of the blind and partially sighted are not being registered, and estimates of incidence and prevalence based on registration should probably be adjusted by a factor of $1 \cdot 1$ to $1 \cdot 4$.

In conclusion we must try to assess the effectiveness of the Blind Register in relation to its purposes. The primary purpose has been identified in relation to the allocation of special financial and other social benefits rather than the deployment of medical care. The prospect of receiving such benefits probably influences the likelihood of registration and the Register, although incomplete, may meet some of its primary functions although there will of course be variation between authorities and difficulties in ensuring the uptake of benefits in every appropriate case (Holman, 1970). However, it is probably not sufficiently accurate for medical research purposes including epidemiological or genetic studies, or for assisting health service policy formulations such as estimating service needs for the blind, or assisting the systematic personnel deployment of medical care to blind people. It is not designed as a medical register and will not adequately serve the general purposes of medical registers. Insofar as research, planning, and health care deployment functions require registration and scheduling systems, they appear to require a redesigned and reorganized process, either in the form of a separate health services exercise, or through appropriate changes in the existing registration process.

Thanks are extended to Miss Mary Dixon who provided valuable help and technical assistance and the staff of the DHSS for their co-operation.

\section{REFERENCES}

ACHEson, E. D. (1968). Record linkage techniques in studies of the aetiology of cancer. Proc. roy. soc. Med., 61, 726.

British Medical Journal (1963). Editorial: cancer registration. 1, 422.
(1968). Special correspondent: running a mental health service. 3,51 .

The Chronically Sick and Disabled Persons Act (1970). 44, Sec. 1(2)b, H.M.S.O., London.

Graham, P. A., Wallace, J., Welsby, E., and Grace, H. J. (1968). Evaluation of postal detection of registrable blindness. Brit. J. prev. soc. Med., 22, 238.

GraY, P. G., and TodD, J. E. (1967). Mobility and Reading habits of the Blind. Government Social Survey. H.M.S.O., London.

Harris, A., Cox, E., and SMith, C. R. W. (1971). Handicapped and Impaired in Great Britain. Office of Population Censuses and Surveys, Social Survey Division. H.M.S.O., London.

Holman, R. (1970). Socially Deprived Families in Britain. (National Council of Social Service). Bedford Square Press, London.

Hopewell, J. P. (1966). Kidney transplant register. Brit. J. Urol., 38, 635.

The INSTITUTE of Municipal Treasurers and ACCOUNTANTS AND THE SOCIETY OF COUNTY TREASURERS (1972). Welfare Service Statistics 1970-71. London.

Mechanic, D. (1969). Medical Sociology, A Selective View. Free Press, New York.

Report of the Department of Health and Social SECURITY (1971). Research and Statistics Division. An Analysis of Forms SPL 651-660 by Standard Region and Local Authority for the Year Ended 31st December 1970 (internal report) D.H.S.S., London.

SorSBY, A. (1966). The Incidence and Causes of Blindness in England and Wales 1948-1962. Ministry of Health. Reports on Public Health and Medical Subjects No. 114. H.M.S.O., London.

Thомas, G. E. (1968). The registration of children at risk of handicap. Med. Offr, 120, 162.

Tubercle, London (1964). Editorial: indices of tuberculosis 45, 66.

WARREN SPRING LABORATORY (1971). The Investigation of Air Pollution. Department of Trade and Industry, Warren Spring Laboratory, Stevenage.

ZBOROwSKI, M. (1960). Cultural components in responses to pain. In Sociological Studies of Health and Sickness, edited by D. Apple, p. 118. McGraw-Hill, New York and London. 